\title{
AVALIAÇÃo DA CONTAMINAÇÃo DO IGARAPÉ DO SABINO (BACIA DO RIO TIBIRI) POR METAIS PESADOS, ORIGINADOS DOS RESÍDUOS E EFLUENTES DO ATERRO DA RIBEIRA, EM SÃO LUÍS, MARANHÃO
}

\author{
Antonio Eduardo Lopes Campos \\ Departamento de Biologia, Universidade Federal do Maranhão, Av. dos Portugueses, s/n, Campus do Bacanga, \\ 65080-040 São Luís - MA, Brasil \\ Gilvanda Silva Nunes* e José Crediciomar Silva de Oliveira \\ Departamento de Tecnologia Química, Universidade Federal do Maranhão, Av. dos Portugueses, s/n, Campus do Bacanga, \\ 65040-080 São Luís - MA, Brasil \\ Ilda Antonieta Salata Toscano \\ Laboratório de Espectroscopia Atômica, Hospital da Universidade Católica de Brasília, Av Areal, lote 22, Taguatinga - DF, \\ Brasil
}

Recebido em17/6/08; aceito em 19/11/08; publicado na web em 12/2/09

\begin{abstract}
EVALUATION OF CONTAMINATION ON SABINO STREAMLET (BASIN RIO TIBIRI) BY HEAVY METALS ORIGINATED FROM WASTE AND EFFLUENTS OF THE RIBEIRA LANDFILL, IN SÃO LUIS ISLAND, STATE OF MARANHÃO, BRAZIL. This work aimed to carry out an environmental monitoring in sabino narrow river (affluent of Tibiri Basin, in São Luís - MA, Brazil), in order to verify the main environmental impacts caused by effluent residues from Ribeira landfill. Chemical analysis and bibliographic and cartographic researches on this ecosystem were also carried out. In addition, heavy metals, such as $\mathrm{Hg}, \mathrm{Pb}$ and $\mathrm{Zn}$, were investigated in water samples by ICP-MS technique. It was observed that the contents of such heavy metals were above the tolerance limits established by the Brazilian legislation, showing a strong impact level on the evaluated ecosystem.
\end{abstract}

Keywords: environmental impacts; heavy metals; Sabino Narrow River.

\section{INTRODUÇÃO}

A contaminação de ambientes por metais pesados foi ignorada até o trágico evento em Minamata, Japão (1932), onde, através da contínua descarga de metil-mercúrio, por efluentes de uma indústria de acetaldeído, houve contaminação da baía, bioacumulação através de cadeia trófica e séria intoxicação ao homem, causando a morte de centenas de pessoas e deformações fetais em gestantes. ${ }^{1}$ Depois desse acidente, o mundo se viu obrigado a controlar os teores de metais pesados nos ambientes aquáticos.

Os metais pesados compreendem aqueles elementos cuja densidade excede $5,0 \mathrm{~g} / \mathrm{cm}^{3}$, diferindo de outros agentes tóxicos por não serem sintetizados nem destruídos pelo homem. ${ }^{2} \mathrm{~A}$ atividade industrial diminui significativamente a permanência desses metais nos minérios, bem como a produção de novos compostos, além de alterar a distribuição destes no planeta. ${ }^{3}$

Os seres vivos necessitam de pequenas quantidades de alguns desses metais, incluindo cobalto, cobre, manganês, molibdênio, vanádio, estrôncio e zinco, para a realização de funções vitais no organismo. Porém, níveis excessivos desses elementos podem ser extremamente tóxicos. Outros metais pesados, como mercúrio, chumbo e cádmio, não possuem nenhuma função dentro dos organismos e sua acumulação pode provocar graves doenças, sobretudo nos mamíferos. Quando lançados como resíduos industriais, na água, no solo ou no ar, esses elementos podem ser absorvidos pelos vegetais e animais das proximidades, provocando graves intoxicações ao longo da cadeia alimentar. ${ }^{4}$

Todas as formas de vida são afetadas pela presença de metais

\footnotetext{
*e-mail: vandasn@terra.com.br
}

pesados, umas mais e outras menos, dependendo da dose e da forma química. Assim sendo, a maior preocupação com estes elementos está relacionada à sua bioacumulação pela flora e fauna aquáticas que acaba por atingir o homem, produzindo efeitos subletais e letais, decorrentes de disfunções metabólicas.

Segundo a Associação Brasileira de Limpeza Urbana e Resíduos Especiais - ABRALPE - são gerados 170 mil t/dia de resíduos urbanos das quais 140 mil t/dia são coletadas e, destes, 60\% não têm destinação adequada, em $61 \%$ dos municípios brasileiros. Dos resíduos industriais são gerados cerca de 82,8 milhões t/ano de resíduos não-perigosos e cerca de 3,8 milhões t/ano de resíduos perigosos, sendo que somente o estado de São Paulo tem um Programa de Gerenciamento de Resíduos. ${ }^{5}$

Recentemente, a Companhia Ingá, indústria de zinco, situada na Ilha da Madeira (RJ), atualmente desativada, transformou-se em uma das maiores áreas contaminadas com lixo tóxico no Brasil. O solo, a água e o mangue da área foram totalmente contaminados por zinco, cádmio, mercúrio e chumbo. Isto vem demonstrar a falta de monitoramento desses resíduos em muitas regiões brasileiras.

O Maranhão não foge a essa realidade. Após visitas e estudos realizados no Aterro da Ribeira em São Luís, no ano de 1998, constatou-se que o mesmo não vinha sendo operacionalizado mediante procedimentos exigidos pelas normas técnicas, tais como, espalhar, compactar e cobrir com terra os resíduos sólidos, formando células de lixo. ${ }^{6}$ De lá para cá, a situação tem se agravado, devido ao acúmulo diário de diversos tipos de resíduos tóxicos. Além disso, não vem sendo executada nenhuma medida de controle desses resíduos, o que tem causado vários impactos ao ambiente, entre os quais pode-se citar: exposição de lixo a céu aberto com o aparecimento de micro e macro vetores transmissores de doenças (artrópodes, roedores e, prin- 
cipalmente, insetos), presença de urubus (risco para o tráfego aéreo, devido à proximidade com o aeroporto Marechal Cunha Machado) e exposição de chorume a céu aberto, contaminando o solo, o lençol freático e, conseqüentemente, o Igarapé do Sabino ou da Ribeira, afluente da Bacia do rio Tibiri.

No presente trabalho, foram quantificados os metais pesados chumbo, mercúrio e zinco nas águas e nos sólidos em suspensão do Igarapé do Sabino, que recebe os efluentes do Aterro da Ribeira. Foram realizados levantamentos cartográficos, de modo a apoiar o estudo, que teve como principal objetivo demonstrar a vulnerabilidade daquele ecossistema aquático.

\section{PARTE EXPERIMENTAL}

\section{Reagentes e adsorvente}

Foram utilizados os seguintes reagentes: ácido nítrico P.A. (65\% pureza, Vetec); soluções estoque a $1000 \mathrm{mg} \mathrm{L}^{-1}$ dos metais pesados $\mathrm{Pb}^{2+}, \mathrm{Hg}^{2+} \mathrm{e} \mathrm{Zn}^{2+}$ (Carlo Erba) e resina trocadora de cátions, fortemente ácida, Chelex ${ }^{\circledR} 100$, constituída de um hidrogel de estireno-divinilbenzeno contendo grupamentos ácidos aminodiacéticos (Lab. Biorad, Califórnia, EUA). A água utilizada para todos os procedimentos foi deionizada em sistema Direct-Q (Millipore Co.). Toda a vidraria e materiais utilizados para as análises dos metais pesados foi lavada abundantemente com água destilada, antes de serem imersos em solução de ácido nítrico a 20\% (v/v) (para material de amostragem) e $5 \mathrm{~mol} \mathrm{~L}^{-1}$ (para vidrarias de uso em análises), durante 3 dias. Após este período, o material foi enxaguado com água deionizada, seco ao ar e embalado com filme de PVC.

\section{Equipamentos}

Para a determinação das concentrações dos metais estudados, foi utilizado um espectrômetro de massas com plasma acoplado indutivamente (ICP-MS) Varian, modelo 700ES, nas seguintes condições operacionais: fluxo do plasma: $15,9 \mathrm{~L} / \mathrm{min}$; fluxo auxiliar: 1,53 L/min; fluxo do gás: 0,17 L/min; fluxo do nebulizador: 0,91 L/ min; potência da RF: 1,34 kW; rotação da bomba: $4 \mathrm{rpm}$; atraso do estabilizador: $10 \mathrm{~s}$.

\section{Amostragem}

Foram selecionados 5 pontos no Igarapé do Sabino para coleta de amostras: ponto zero (controle), no alto curso (montante do Aterro da Ribeira, $2^{\circ} 38^{\prime} 26,04$ 'S e $44^{\circ} 14^{\prime} 37,75^{\prime \prime} \mathrm{W}$ ); ponto 1 , no médio curso (próximo ao Aterro da Ribeira, onde os efluentes do Aterro são lançados na água, a $02^{\circ} 38^{\prime} 49,1^{\prime}$ ' S e 44 14' 50,8' W de Gmt); ponto 2 , no médio curso (a $02^{\circ} 38^{\prime} 31^{\prime \prime} \mathrm{S}$ e $44^{\circ} 14^{\prime} 18,5^{\prime \prime} \mathrm{W}$ de Gmt); ponto 3 , no médio curso (próximo ao lugar chamado Campina, a $02^{\circ} 38^{\prime} 34,9^{\prime}$ ' S e 44 13 ' 73,8" W de Gmt); ponto 4, no baixo curso, onde o igarapé deságua no rio principal, o rio Tibiri (a $02^{\circ} 38^{\prime} 14,1$ " S e $44^{\circ} 13^{\prime} 48,4$ " W de Gmt). A distância entre estes pontos foi de aproximadamente $1,5 \mathrm{~km}$. As coletas foram realizadas mensalmente, de fev/2006 a jan/2007. Os locais de coleta foram estabelecidos de forma a assegurar que a amostragem fosse significativa para a caracterização do sistema.

\section{Análises e levantamentos cartográficos}

Foram feitas interpretações das bases cartográficas da área de estudo, da carta topográfica elaborada pela Diretoria do Serviço Geográfico do Ministério do Exército - DSG/ME (1980, escala 1:10000) e das cartas elaboradas por Silva. ${ }^{7}$

\section{Preparo das amostras e análises dos metais pesados}

Após coleta em frascos do tipo PVC, as amostras foram acondicionadas a $4{ }^{\circ} \mathrm{C}$, e imediatamente levadas ao laboratório, tendo sido filtradas em membranas de acetato de celulose $(0,45 \mu \mathrm{m})$. Após a filtração, as amostras foram pré-concentradas através de uma coluna constituída de uma seringa hipodérmica plástica $(10 \mathrm{~mL}$ de capacidade), recheada com resina Chelex 100. Ao passar um volume de 200 $\mathrm{mL}$ da amostra de água pela coluna, o material adsorvente tomou, imediatamente, a consistência de um hidrogel. A passagem da amostra se deu em um fluxo de aproximadamente $2 \mathrm{~mL} / \mathrm{min}$, e teve a finalidade de adsorver os metais pesados de interesse. Em seguida, procedeu-se à eluição dos analitos com $30 \mathrm{~mL}$ de $\mathrm{HNO}_{3} 4 \mathrm{~mol} \mathrm{~L}^{-1}$ (fator de préconcentração: 20 vezes); o eluato foi recolhido e submetido à análise por ICP-MS no Laboratório de Saúde e Meio Ambiente do Hospital da Universidade Católica de Brasília, Taguatinga-DF.

\section{RESULTADOS E DISCUSSÃO}

\section{Localização e descrição da área de estudo}

O Igarapé do Sabino é um afluente da margem direita do Rio Tibiri. A Bacia do Tibiri localiza-se no Município de São Luís-MA, na parte sudeste da Ilha do Maranhão, entre as coordenadas $02^{\circ} 35^{\prime}$ e $02^{\circ} 43^{\prime}$ Sul e $44^{\circ} 10^{\prime}$ e $44^{\circ} 18^{\prime}$ W de Greenwich. Limita-se a leste com a bacia do Rio Tijupá e a bacia do Rio Jeniparana; a oeste com o Distrito Industrial de São Luís; ao norte com o Aeroporto Marechal Cunha Machado e o Parque de Exposição Agropecuária e, ao sul, com a baía de São José, onde deságua.

\section{Avaliação química da qualidade da água}

Entendendo que os recursos hídricos constituem indicadores das condições ambientais, foi realizado um monitoramento no Igarapé do Sabino; a presença de metais pesados indicou forte interação entre o despejo de efluentes na água e sua relação na degradação ambiental. Evidenciou, ainda, a deficiente gestão do aterro, no qual não têm sido realizados procedimentos obrigatórios para evitar este tipo de contaminação, tais como o monitoramento das águas superficiais e subterrâneas e a drenagem do lixo percolado para as lagoas de tratamento.

Grande quantidade de chorume produzido pelo lixo do Aterro da Ribeira vem sendo lançado continuamente no Igarapé do Sabino. O chorume, conjuntamente com a água das chuvas, encarrega-se de lixiviar compostos orgânicos presentes nos aterros sanitários para o meio aquático. Esse líquido tem atingido as águas do igarapé, mas também pode atingir os lençóis freáticos, poluindo esta importante fonte de água natural. A elevada carga orgânica presente no chorume faz com que seja extremamente poluente e danoso às regiões por ele atingidas.

Os líquidos percolados e o chorume contaminam o igarapé, não só por matéria orgânica, mas também por metais pesados; estes, por sua vez, podem ser consumidos pelos mariscos e peixes, tornando-se cumulativos, até serem consumidos pelo homem. Isto é particularmente alarmante, já que grande parte da população ribeirinha vive da pesca, utilizando o rio como fonte de alimento e renda. Neste trabalho, não foi feita uma avaliação da presença dos metais pesados em amostras biológicas, mas a elevada concentração dos elementos nas amostras de água serve como um indicador da contaminação do ecossistema aquático.

A química estuarina é complexa, devido à natureza dinâmica do ambiente, às suas reações heterogêneas e às escalas de tempo hidrodinâmico. Existem evidências de que a partição e a especiação de metais traço desempenham um papel central na reatividade biogeoquímica das águas naturais, e a importância da complexação 
orgânica em especiação tem sido constantemente enfatizada. Porém, os efeitos da complexação nos processos de adsorção/dessorção no material particulado e seus importantes efeitos na partição, especiação e mobilidade não são ainda completamente entendidos. ${ }^{8}$

Em sistemas aquáticos, apenas uma pequena fração do metal dissolvido existe na forma livre, porque os íons metálicos formam complexos com uma grande variedade de ligantes inorgânicos e orgânicos, adsorvem-se em colóides e/ou em matéria em suspensão. As formas do metal que são mais biodisponíveis e que, dependendo de sua concentração, podem ser tóxicas, são em ordem decrescente: 0 metal na forma de íon hidratado, complexos orgânicos e inorgânicos lábeis e alguns complexos do metal que são lipossolúveis, estes últimos em bem menor expressão, dependendo do sistema em estudo. ${ }^{9}$

As águas do Igarapé do Sabino não apresentam, ainda, características de ambiente eutrofizado, muito provavelmente em decorrência do regime de marés, que influencia diretamente a dinâmica e a movimentação das espécies químicas presentes. As características de solo da região de entorno e do sedimento (arenoso, pouco ácido e bem adaptado às condições de oligotrofismo) não permitem a formação de sulfeto livre. Além disso, a decomposição da matéria orgânica tem sido promovida, basicamente, por processos aeróbios, o que limita a presença do íon sulfeto e, conseqüentemente, a precipitação de sulfetos insolúveis de metais pesados.

A eficiência da resina Chelex-100 como fixadora e trocadora de cátions foi recentemente testata, com recuperações médias de 75,5 e $86,1 \%$, para os elementos $\mathrm{Pb}$ e Cd, respectivamente..$^{10} \mathrm{Assim}$, este material adsorvente foi eficiente na pré-concentração dos metais investigados neste trabalho, a maioria dos quais encontrados na forma livre.

Como pode ser visto nas Figuras 1 e 2, o $\mathrm{Pb}$ foi encontrado na maior parte dos meses, no período estudado, tanto na água como nos sólidos em suspensão; nos meses de março, abril, setembro e outubro/2006, os teores de $\mathrm{Pb}$ estiveram acima do nível máximo estabelecido pela legislação brasileira (Resolução n. 357 do CONAMA, de 17/3/2005). ${ }^{11} \mathrm{O}$ aumento nos teores de $\mathrm{Pb}$ nos meses de março e abril/2006 pode ter ocorrido em função das máximas de precipitação nesse período, o que provocou o carreamento de grande quantidade de material percolado do aterro para a água do Igarapé.

Os principais usos do $\mathrm{Pb}$, na ilha de São Luís, estão relacionados às indústrias extrativas, de baterias, tintas e corantes, cerâmica, cabos, tubulações e munições. Como na maioria dos casos, grande parte do chumbo encontrado no solo e nas águas superficiais do igarapé origina-se de baterias e pilhas que são jogadas no Aterro da Ribeira, sem nenhum acondicionamento adequado.

Várias são as consequiências de intoxicação por chumbo. O sistema nervoso, a medula óssea e os rins são considerados órgãos críticos para este metal, que interfere nos processos genéticos ou cromossômicos e produz alterações na estabilidade da cromatina, inibindo o reparo de DNA e agindo como promotor de câncer. ${ }^{12}$

Alguns casos de envenenamento por $\mathrm{Pb}$ foram registrados em Bauru (SP), onde uma indústria de baterias e acumuladores de eletromotivos lançava seus efluentes no manancial da região. ${ }^{13} \mathrm{Em}$ estudos realizados por Souza, ${ }^{14}$ no Igarapé dos Tanques (RO), foram detectadas concentrações altas dos metais pesados $\mathrm{Hg}, \mathrm{Mn}, \mathrm{Zn}, \mathrm{Cr}$, $\mathrm{Cu}, \mathrm{Pb}, \mathrm{Co}, \mathrm{Fe}$ e $\mathrm{Cd}$ em amostras de sedimentos e particulados em suspensão, caracterizando uma contaminação considerável nesse sistema aquático. Nos ecossistemas aquáticos, algumas populações de invertebrados são mais sensíveis que outras, e a estrutura das comunidades pode ser diversamente afetada pela contaminação por $\mathrm{Pb}$; entretanto, populações de áreas poluídas podem mostrar maior tolerância ao $\mathrm{Pb}$ em relação às de área não poluídas. ${ }^{15}$

As Figuras 3 e 4 mostram que, na maior parte do período investigado, os teores de $\mathrm{Zn}$, na água e nos sedimentos, estiveram acima do permitido pela legislação brasileira, nas amostras de sedimentos.

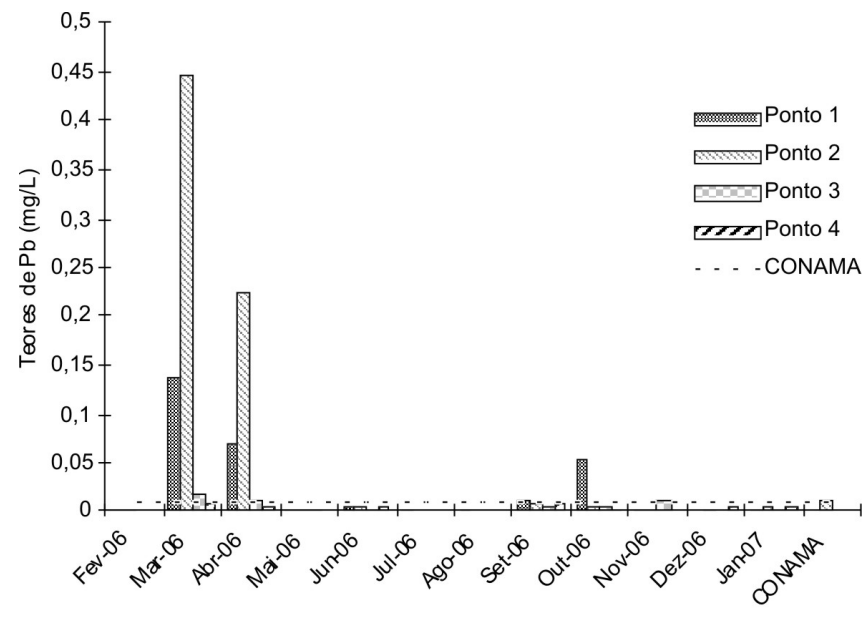

Figura 1. Variação dos teores de Pb na água do Igarapé do Sabino, em função da localidade e do tempo

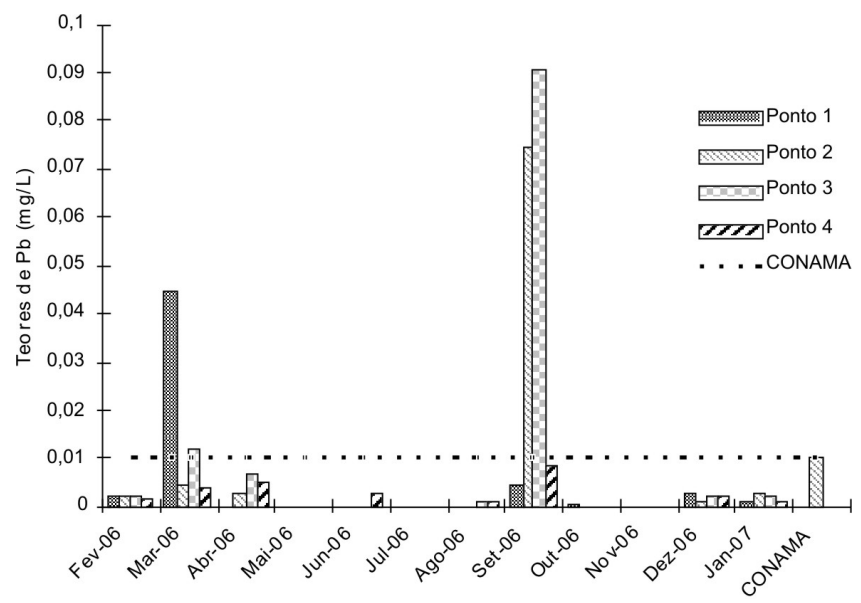

Figura 2. Variação dos teores de Pb nos sólidos em suspensão no Igarapé do Sabino, em função da localidade e do tempo

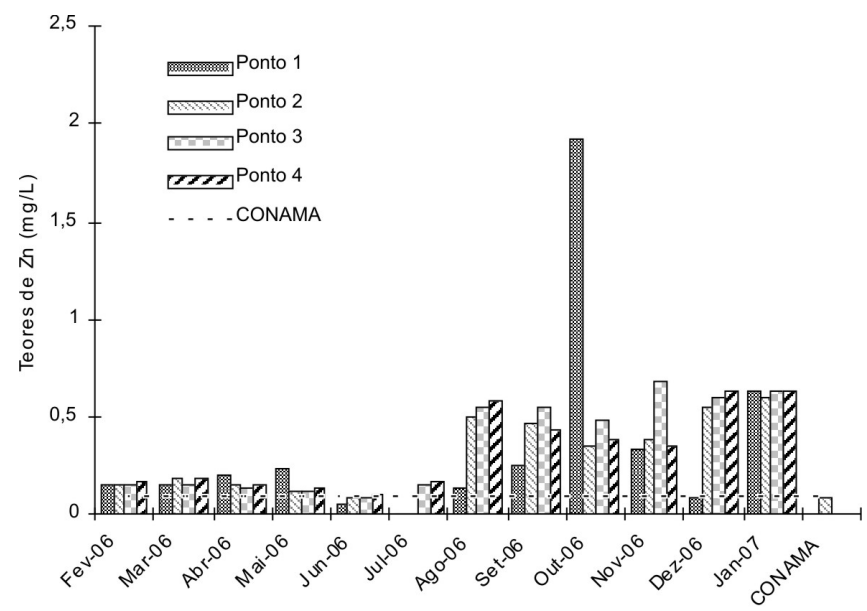

Figura 3. Variação dos teores de Zn na água do Igarapé do Sabino, em função da localidade e do tempo

O Zn é um elemento importante no metabolismo humano e sua deficiência pode acarretar problemas de crescimento, porém altas concentrações podem causar intoxicações e alterações morfológicas aos seres vivos, além de proporcionarem alterações no sabor da água. ${ }^{16}$ As principais fontes poluidoras por $\mathrm{Zn}$ têm sido a galvanoplastia, os pigmentos de pintura, os inseticidas e a mine- 


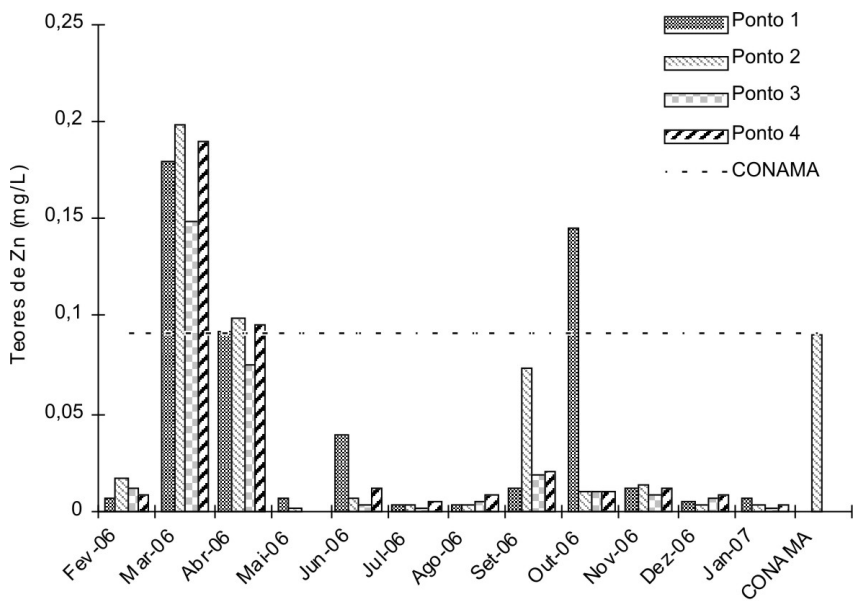

Figura 4. Variação dos teores de Zn nos sólidos em suspensão no Igarapé do Sabino, em função da localidade e do tempo

ração. ${ }^{15}$ Em estudos realizados no Estuário de Cananéia (SP), no período de dez/1996 a set/1997, foram encontradas concentrações de $\mathrm{Zn}$ em ostras de mangue Crassostrea brasiliana (uma espécie estuarina de ocorrência em quase toda a costa brasileira, desde Santa Catarina até o Maranhão), em níveis acima da legislação em vigor (Decreto 55.871/65 de Brasília, DF, que estabelece o limite de $30,0 \mathrm{mg} / \mathrm{kg}) .{ }^{17}$

A progressiva utilização do $\mathrm{Hg}$ para fins industriais e o emprego de compostos mercurais, durante décadas na agricultura, resultaram no aumento significativo da contaminação ambiental, especialmente da água e dos alimentos. Uma das razões que contribuem para o agravamento dessa contaminação é a biotransformação, por bactérias, do mercúrio inorgânico em metilmercúrio, que é o processo responsável pelos elevados níveis de metal pesado no ambiente. ${ }^{18}$ Nos processos de extração, o mercúrio é liberado no ambiente principalmente a partir do sulfeto de mercúrio; o mercúrio e seus compostos são encontrados na produção de cloro e soda cáustica (eletrólise), em equipamentos elétricos e eletrônicos (baterias, retificadores, relés e interruptores), em aparelhos de controle (termômetros e barômetros), em tintas (pigmentos), em amálgamas dentárias, em fungicidas, em lâmpadas de mercúrio, entre outros. ${ }^{19}$

No Igarapé do Sabino, em praticamente todos os meses do ano, os teores de mercúrio na água e nos sólidos em suspensão estiveram acima das concentrações permitidas (Figuras 5 e 6). Isto é preocupante, quando se consideram os organismos que vivem nesse ecos-

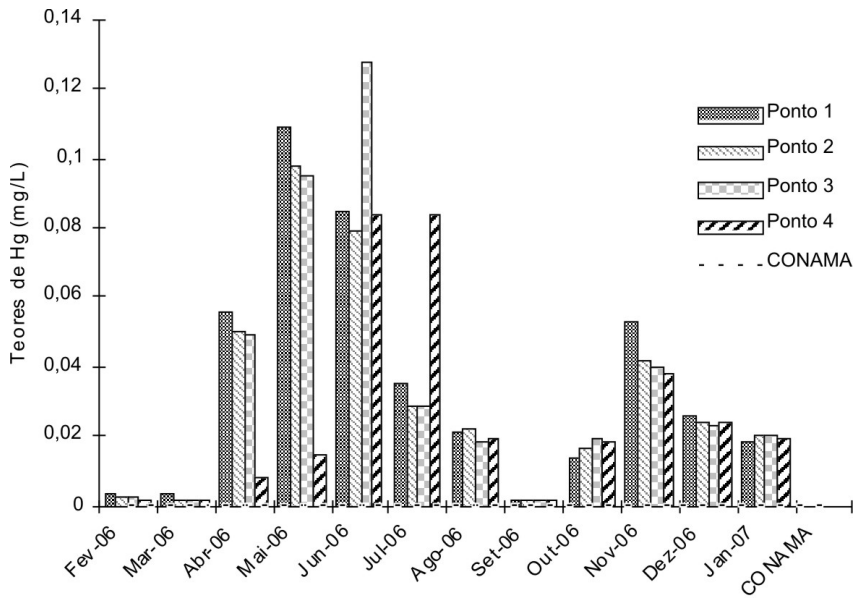

Figura 5. Variação dos teores de Hg na água do Igarapé do Sabino, em função da localidade e do tempo

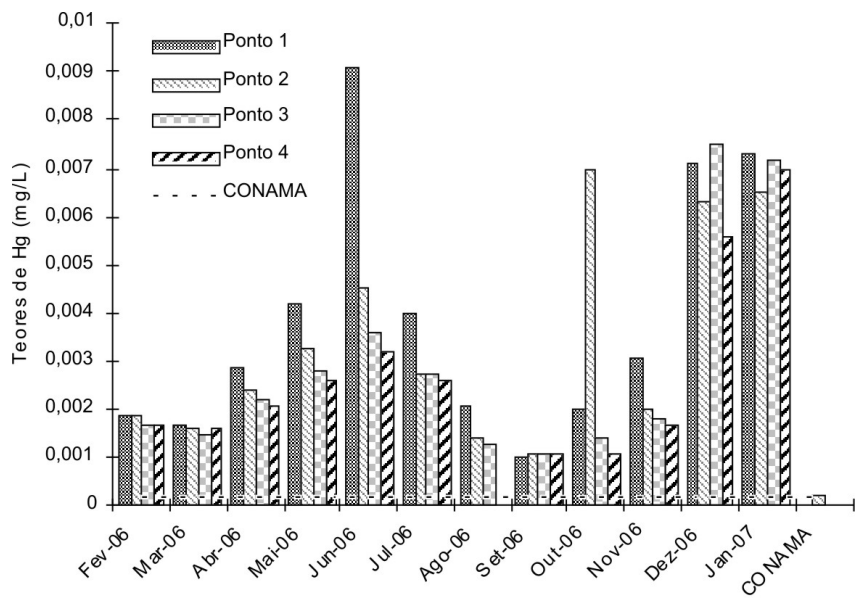

Figura 6. Variação dos teores de Hg nos sólidos em suspensão no Igarapé do Sabino, em função da localidade e do tempo

sistema aquático e também a população ribeirinha que se alimenta desses indivíduos. Provavelmente, o $\mathrm{Hg}$ encontrado no Igarapé do Sabino origina-se de lâmpadas fluorescentes, baterias de carro e de celulares e pilhas.

No âmbito do plâncton, o Hg e, sobretudo, os compostos organomercúricos reduzem a fotossíntese do fitoplâncton. Em meio redutor rico em sulfeto - que não é o caso - este metal pode apresentar-se precipitado (associado com os sulfetos), o que acaba enriquecendo o sedimento. O mercúrio combina-se fortemente com proteínas dos seres vivos e age especificamente sobre os tecidos dos rins, destruindo a capacidade destes órgãos em remover do sangue produtos de eliminação. A intoxicação por mercúrio pode ainda causar a destruição de células nervosas, gerando paralisia, irritabilidade, insanidade e depressão. ${ }^{20}$

Em estudos realizados por Kuno, ${ }^{21}$ na bacia Paraguai, no Alto Pantanal (MS), foram detectados teores de $\mathrm{Hg}$ em peixes, sedimentos e material particulado em suspensão na água, sendo observada forte contaminação do ambiente.

Como já comentado, a presença de $\mathrm{Hg}$ em ambientes aquáticos é fato digno de atenção, devido aos impactos à biota e ao efeito cumulativo, ao longo da cadeia trófica. Pode-se inferir que, possivelmente, os organismos aquáticos que vivem na água do Igarapé do Sabino devem estar contaminados por mercúrio e, conseqüentemente, vêm intoxicando, aos poucos, a população que se alimenta desses indivíduos.

\section{CONCLUSÃO}

Os resultados aqui apresentados são preocupantes, no que se refere à manutenção da qualidade dos recursos hídricos e da biota do Igarapé do Sabino. O quadro de degradação detectado certamente vem contribuindo de forma significativa para um desequilíbrio do ecossistema aquático.

Embora este igarapé seja muito importante para um número significativo de famílias que utilizam suas águas para as mais diversas atividades, e apesar dos impactos visíveis provocados pela falta de gestão do aterro próximo, comprovados pelas análises químicas, não havia até o final desta pesquisa, nenhum estudo investigatório e científico sobre a situação de descaso em relação aos perigos químicos aos quais tal comunidade vem sendo submetida cotidianamente.

Apesar da evidente necessidade de um estudo mais aprofundado, envolvendo uma avaliação dos níveis de contaminação por metais pesados em organismos aquáticos pertencentes ao igarapé, estes resultados preliminares permitem-nos concluir que existe um caso 
grave de contaminação por estes metais. A quebra do estado de invariabilidade sustentada em que se encontram todos os elementos que compõem este ecossistema aquático, desde os organismos aquáticos até a própria mata ciliar, tem afetado, inexoravelmente, a qualidade de vida da população ribeirinha.

\section{MATERIAL SUPLEMENTAR}

Em http://quimicanova.sbq.org.br encontram-se disponíveis os mapas para localização do Aterro da Ribeira e dos pontos de coleta na Sub-bacia do Sabino, na forma de arquivo PDF, com acesso livre.

\section{AGRADECIMENTOS}

À Fundação de Amparo à Pesquisa e ao Desenvolvimento Cientifico e Tecnológico do Maranhão - FAPEMA e ao Conselho Nacional de Desenvolvimento Científico e Tecnológico - CNPq, pelo apoio financeiro.

\section{REFERÊNCIAS}

1. Vasquez, M. J.; Albuín, M.; Carro, A. M.; Lorenzo, R. A.; Cela, R.; Chemosphere 1999, 39, 1211.

2. Galvão, P. M. A.; Monografia, Universidade Federal do Rio de Janeiro, Brasil, 2003.

3. Esteves, F. A.; Fundamentos de Limnologia, $2^{\text {a }}$ ed., Interciência: Rio de Janeiro, 1998.

4. Mohn, W. W.; Martin, V. J. J. E.; Yu, Z. T.; Water Sci, Technol. 1999, 40, 273.

5. Associação Brasileira de Limpeza Urbana e Resíduos Especiais; Panorama dos Resíduos Sólidos no Brasil, ARALPE: São Paulo, 2007.
6. Campos, A. E. L.; Estudo Ambiental sobre o Aterro Sanitário da Ribeira, Edufma: São Luís, 1998.

7. Silva, Q. D.; Dissertação de Mestrado, Universidade Federal do Ceará, Brasil, 2001.

8. Morris, A. W.; Sci. Total Environ. 1990, 98, 253.

9. Tessier, A.; Campbell, P. G. C.; Hidrobiology 1987, 149, 43.

10. Oliveira, J. C. S.; Silva, V. A. G.; Silva, M. N.; Nunes, G. S.; Franco, T. C. R. S.; Resumos da $31^{a}$. Reunião Anual da Sociedade Brasileira de Química, Águas de Lindóia, Brasil, 2008.

11. BRASIL. Conselho Nacional do Meio Ambiente; Resolução CONAMA n. 357, de 17 de março de 2005, Brasília, 2005.

12. Paoliello, M. M. B.; Chasin, A. A. M.; Ecotoxicologia do Chumbo e Seus Compostos, CRA: Salvador, 2001.

13. http://www. arvore.com.br/artigos/htm_2002/ar1004_6.htm, acessada em Novembro 2005.

14. Souza, D. O.; Monografia, Universidade Federal de Rondônia, Brasil, 2006.

15. WHO - World Health Organiz, IPCS; Environmental Health Criteria 85 - Lead - Environmental Aspects, Geneva, 1989.

16. Salgado, P. E. T. Em Fundamentos de Toxicologia; Oga, S., ed.; 2 ${ }^{\mathrm{a}}$ ed.; Atheneu: São Paulo, 1996.

17. Machado, I. C.; Maio, F. D.; Kira, S. C.; Carvalho, M de F. H.; Rev. Int. A. Lutz, 2002, 61, 13.

18. Nascimento, E. S.; Chasin, A. A. M.; Ecotoxicologia do Mercúrio e Seus Compostos, CRA: Salvador, 2001.

19. Marins, R. V.; Lacerda, L.; Vilas Boas, R. C. Em Mercury Contamination Sites: Characterization, Risk Assessment and Remediation; Ebinghaus, R.; Turner, R. R.; Lacerda, L. D.; Vasiliev, O.; Salomons, W., eds.; Springer Verlag: Berlin, 1999.

20. Moraes, A. J.; Manual para Avaliação da Qualidade da Água, RIMA: São Carlos, 2001

21. Kuno, R.; Dissertação de Mestrado, Universidade de São Paulo, Brasil, 2003. 


\section{AVALIAÇÃO DA CONTAMINAÇÃO DO IGARAPÉ DO SABINO (BACIA DO RIO TIBIRI) POR METAIS PESADOS, ORIGINADOS DOS RESÍDUOS E EFLUENTES DO ATERRO DA RIBEIRA, EM SÃO LUÍS, MARANHÃO}

\section{Antonio Eduardo Lopes Campos}

Departamento de Biologia, Universidade Federal do Maranhão, Av. dos Portugueses, s/n, Campus do Bacanga, 65080-040 São Luís - MA, Brasil

Gilvanda Silva Nunes* e José Crediciomar Silva de Oliveira

Departamento de Tecnologia Química, Universidade Federal do Maranhão, Av. dos Portugueses, s/n, Campus do Bacanga, 65040-080 São Luís - MA, Brasil

Ilda Antonieta Salata Toscano

Laboratório de Espectroscopia Atômica, Hospital da Universidade Católica de Brasília, Av Areal, lote 22, Taguatinga - DF, Brasil

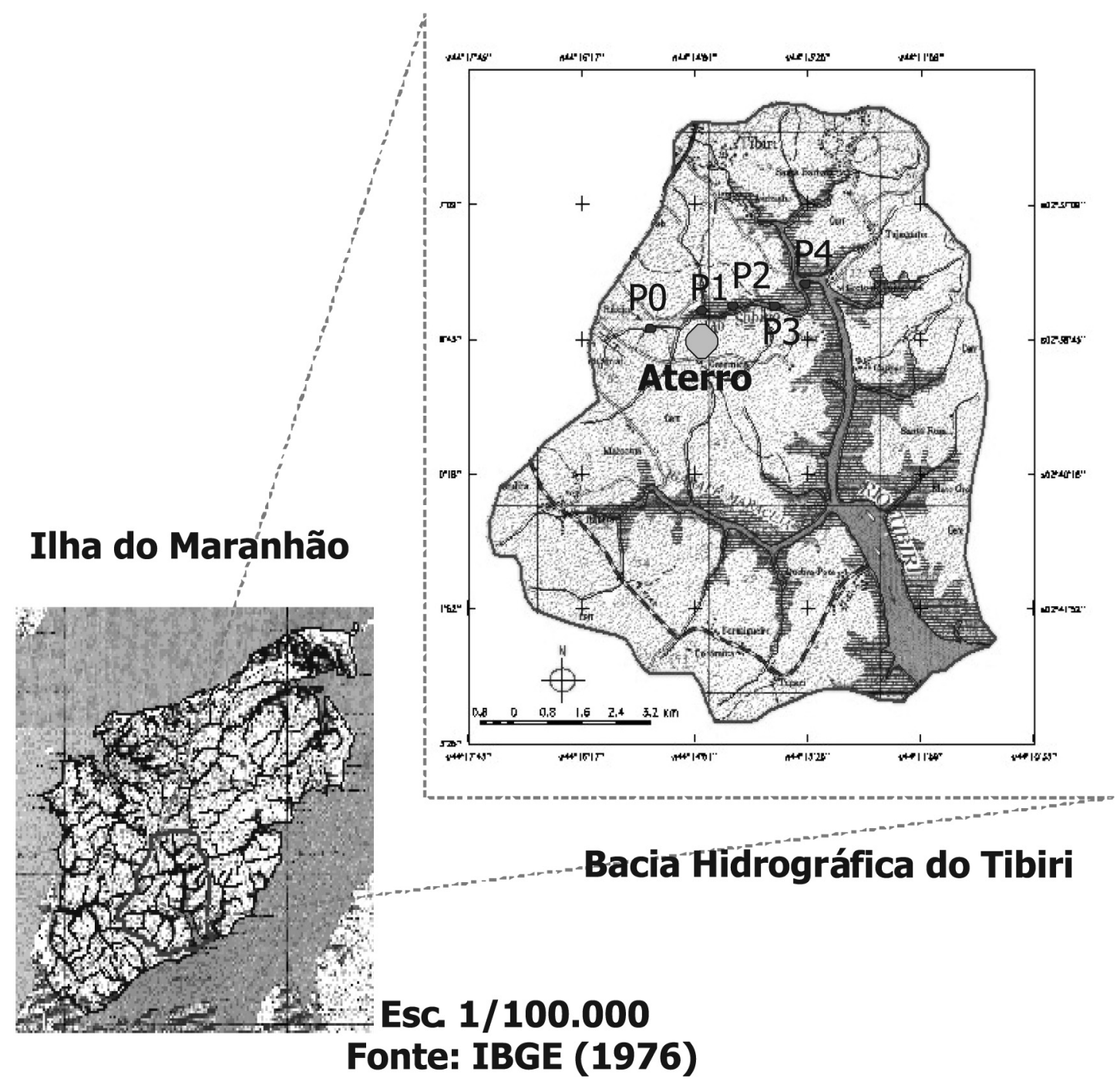

Figura 1S. Localização do Aterro da Ribeira e dos pontos de coleta na Sub-bacia do Sabino, em São Luís do Maranhão. Adaptado da ref. 6 


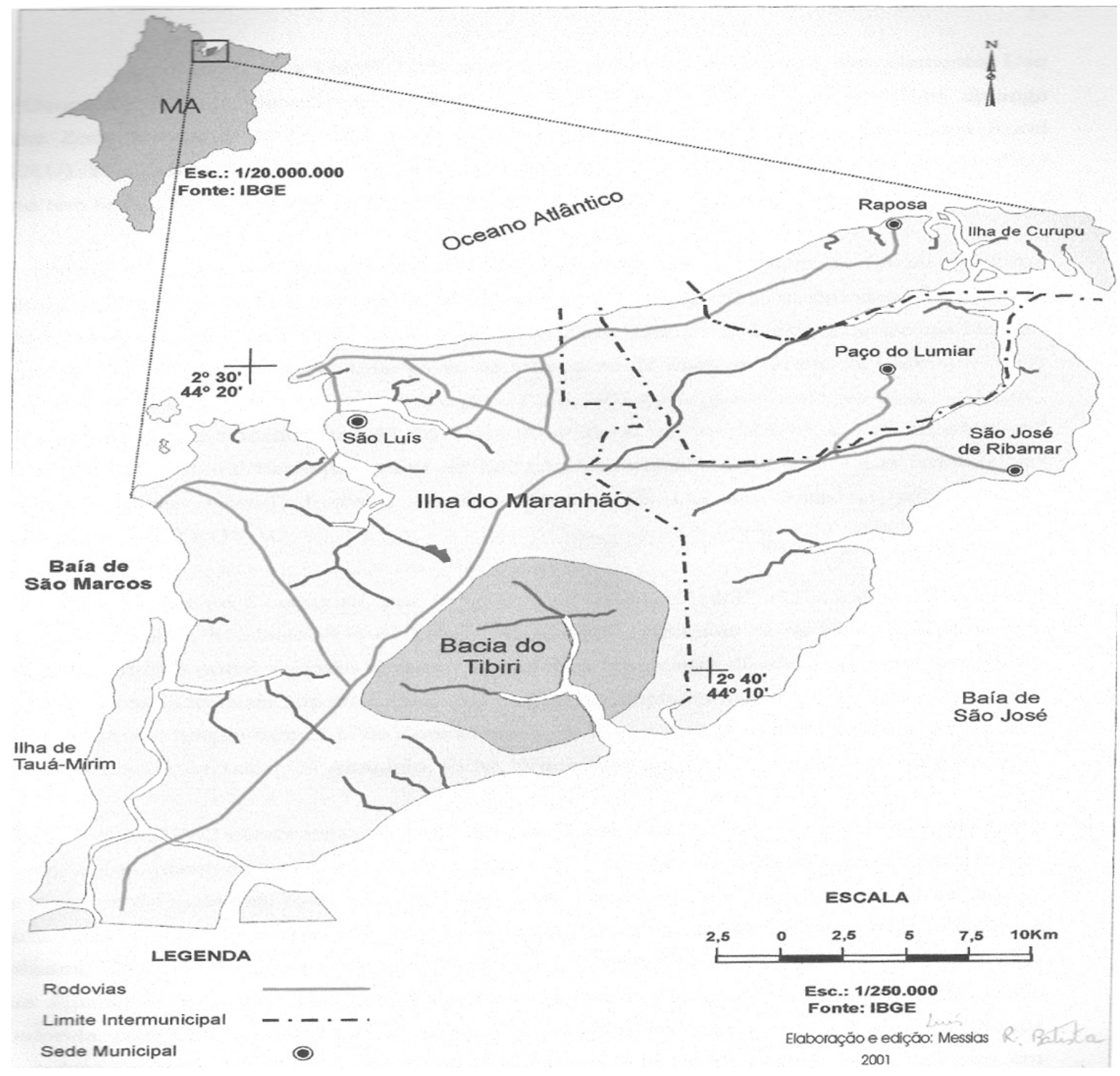

Figura 2S. Localização da Bacia do Tibiri, em São Luís do Maranhão. Adaptado da ref. 6 